Pain Physician. 2004;7:249-255, ISSN 1533-3159

\title{
The Role of Cervical Discography in Interventional Pain Management
}

\author{
Vijay Singh, MD
}

Cervical discography, cervical disc puncture with contrast dye injection under fluoroscopic guidance, is a commonly used modality in the evaluation of patients with intractable neck pain. MRI and CT scans are the initial tests in the diagnostic evaluation of symptomatic cervical discs. These provide noninvasive and accurate assessment of disc anatomy and pathologic change. Since correlation of pain with abnormalities of structural anatomy is not always reliable, direct injection of cervical discs is done to precisely localize and identify painful discs. The improvements in contrast media, imaging technique, meticulous attention to aseptic technique combined with use of antibiotics have resulted in very low rates of complications. Cervical discography is a diagnostic procedure used in complementary fashion with other imaging techniques to yield the precise disc level responsible for pain and to aid in planning treatment.

Keywords: Discography, cervical discography, cervical discs, neck pain, discitis
Neck pain is a common complaint among the general population in the U.S. $(1,2)$. Reports show that $35-40 \%$ of individuals will suffer from neck and arm pain and 30\% may develop chronic pain symptoms. Of 100,000 people, there are 83.2 cases per year that demonstrate cervical radiculopathy (3) and 38.4 cases per 100,000 who display definite radiculopathy proven to be due to disc prolapse (4). In spite of attempts to use rational selection algorithms to diagnose the source of cervical pain, discussion in the literature continues because no one diagnostic modality can provide the information required in every case. Complementary procedures are used to acquire the fullest picture of pathology. Techniques such as MRI, CT scanning and myelography provide detailed resolution of abnormal anatomy. The images, however accurate, do not report that a particular lesion as the cause or source of symptoms (5). Correlation of reported symptoms with information obtained in imaging may not be sufficiently reliable to unequivocally determine the location or degree that symptoms and pathology coincide (6-9).

From Pain Diagnostic Associates, Niagara, Wisconsin. Address Correspondence: Vijay Singh, MD, Pain Diagnostics Associates, 1601 Roosevelt Road, Niagara WI 54151

E-mail:vsingh@netnet.net

Support: Nothing of value received from a commercial entity related to this research

Conflict of Interest: None
This was the position taken by Roth (10) in 1975 when he defined a cervical discogenic (painful disc) syndrome to be uniquely diagnosed by analgesic discography. Over two years he found the technique of analgesic discography precisely able to locate and identify a pain-producing disc. His study marked the first time analgesic disc injection was advocated for diagnosis in the cervical discogenic pain syndrome. Provocative discography, the practice of reproducing a patient's pain with injection of contrast followed by local anesthetic injection to confirm the presence of a painful disc, has emerged as a useful technique in the evaluation of chronic cervical pain.

\section{Historical Considerations}

Although Lindblom (11) studied the effects of disc puncture in 1948 and coined the term discography, Schmorl (12) in 1921 first injected a disc for radiographic visualization. Hirsch (13) in 1948 followed Lindblom's work with the first clinical study of disc injection in 16 patients using saline and procaine to localize lumbar pain. Subsequent surgery showed an absence of signs of disc injury. Early data on intradiscal pressure was obtained by Erlacher (14) in 1952 who pressurized 200 discs removed at autopsy to $300 \mathrm{kPa}$ without any instance of disc rupture. Also in the 1950s, Smith and Nichols (15), and independently Cloward (16), in work done to evaluate patients with chronic neck, shoulder and headache pain, published procedures for the direct injection of cervical discs. Each group published nearly simultaneously, without the knowledge of the others' work. The techniques were similar, with similar indications and clinical findings being reported in a series of papers. Both authors reported that injection into an abnormal disc could produce pain and that the finding of a painful disc correlated well with increasing age. Each considered the pain response upon injection more relevant than the radiographic appearance of the disc. Each also found that normal cervical discs accepted fairly small volumes $(0.25$ $\mathrm{mL}$ to $0.5 \mathrm{~mL}$ ) and that injection of normal discs was not painful.

These surgeons developed their techniques for cervical disc excision and bony fusion using an anterior approach. To select the disc level for the surgical procedure, both groups used cervical disc injection as a diagnostic technique to support their choice. As a diagnostic technique, cervical discography in the 1960s was accepted by some and criticized by others. Still being a relatively new procedure, basic clinical findings and their relevance were under study and evaluation.

Holt's (17) 1968 study of volunteer, asymptomatic prison subjects is noted for its negative conclusions, that discography was ineffective and useless. Simmons et al (18) did a careful re-examination of his study and conclusions in 1988 and ex- 
posed significant deficiencies and flaws in the study. The selection process of inmate subjects was questioned because bias was not controlled, the contrast agent used was an irritant itself, fluoroscopic guidance was not utilized, monitored anesthesia was not used, and the technique itself was suspect in the Simmons group opinion. As an example, extravasation of contrast material was noted with every injection; it continued even with reduction in the amount injected. Its significance was not investigated by Holt. Holt rejected correlation of pain with any amount of material injected as without value. Control subjects were not used. Any critical look at this study today is harsh in its appraisal. Briefly, Simmons et al (18) concluded that the Holt paper no longer be considered as either scientific or authoritative evidence in any discussion of discography.

In the time since the basic knowledge of the physiology and pathology of the disc has expanded. The technique of cervical discography has undergone modification and significant advancement. Fluoroscopic guidance is routine, contrast dye is far less toxic and with greater numbers of discograms being successfully done, experience has been gained so that the practice of cervical discography is safe and well established. Although cervical may be considered controversial by some, most discographers consider discography to be an essential part of a diagnostic evaluation of chronic cervicogenic pain (19).

\section{Anatomic Considerations}

Differences as well as similarities exist between cervical discs and others in the spinal column. Symptoms solely due to disc herniation are less common in the cervical region than in the lumbar region. Herniation posteriorly and laterally is first prevented by cervical facet joints, which form a bony barrier between the disc and the nerve root, and second, by the dense posterior longitudinal ligament which encloses the disc posteriorly. The nucleus also lies much more anteriorly in the cervical disc than in the lumbar disc, and its movement posteriorly is correspondingly much more difficult and unlikely. In adults, the cervical disc is composed of fibrocartilaginous material, which makes up the annulus fibrosus, with very little nucleus pulposus present. The cervical disc annulus does not consist of concentric laminae of collagen fibers as are found in lumbar discs. Rather, a crescent-shaped mass of collagen fibers thicker anteriorly and tapered laterally toward the uncinate process characterizes the annulus fibrosus. It is more like a crescentshaped anterior interosseous ligament than a ring of circular fibers surrounding a nucleus pulposus $(20,21)$. For the discographer, this has some practical meaning, as healthy cervical discs only accept small amounts of contrast media, usually on the order of $0.25 \mathrm{~mL}$ to $0.5 \mathrm{~mL}$, due to the very small nucleus and small size of the disc. Injection of greater volumes usually means extravasation of contrast, with little resistance upon injection being appreciated by the discographer.

The volume of nucleus in the adult cervical intervertebral disc has been studied in cadavers in 1983 by Saternus and Bornscheuer (22). They report that $75 \%$ of discs at C2-C3, C3-C4 and C7-T1 accepted less than $0.5 \mathrm{~mL}$ and $50 \%$ of discs at $\mathrm{C} 4-\mathrm{C} 5, \mathrm{C} 5-\mathrm{C} 6$ and C6-C7 accepted less than $0.5 \mathrm{~mL}$. They also found that discs accepting more than $0.5 \mathrm{~mL}$ frequently demonstrated leakage from the posterolateral or uncovertebral portions of the annulus.

Kambin et al (23) in 1980, have made intradiscal volumetric determinations during discography at the time of cervical disc surgery and found that normal-appearing discs accepted $0.2 \mathrm{~mL}$ to $0.4 \mathrm{~mL}$ of contrast while maintaining sustained intradiscal pressures. Lower pressures were associated with higher volumes and posterior escape of solution. It can be concluded that a normal cervical nucleus will be filled by less than $0.5 \mathrm{~mL}$ of solution.

Anatomists usually make a distinction between the posterior or thinner part and the anterior or thicker portion of the cervical disc. A feature of cervical discs is the usual development in the first two decades of life of horizontal clefts or fissures in the annular tissue, thought to be a functional adaptation to maintain rotational ability as the elastic nature of the annulus decreases with age (3). These are referred to as joints of Luschka by many authors $(20,21,24-26)$.

The uncovertebral articulations, or the joints of Luschka, warrant consideration. The lateral and posterolateral areas of the disc are relatively thinner than the anterior areas and this thinning of the annulus results in linear clefts that communicate with the nucleus. The clefts have not been reported in any patients except adults $(20,21)$. Clefts filling with contrast during discography also have been noted only in adults. They vary in size and configuration and may fill asymmetrically with contrast. Dispersal of contrast posterolaterally into clefts or joints of Lusch$\mathrm{ka}$ is not a result of degeneration of the disc but rather reflects maturation of the adult disc (24). Degeneration in adulthood is common.

The cervical discs may dehydrate earlier than lumbar discs. Deterioration of the nucleus occurs early in the adult, and it may be absent after the age of 35 to 40 . Characterization of the pathologic changes in adult intervertebral cervical discs was done by Gen (27) in 1990 in discs obtained at autopsy. He examined discs by plain roentgenography, discography, CT discography and histologically with morphologic measurements. His data revealed that the anterior portion of discs became thinner with aging. The nucleus, initially located slightly anterior to the center of the disc, tended to migrate to the posterior with aging and the anteroposterior diameter showed a gradual decrease with aging.

Cervical nerve roots branch off the spinal cord laterally through the intervertebral foramina. Radicular symptoms result if the posterior cervical disc herniates laterally and impinges on the nerve root. In 1993, Dubuisson et al (28) reported on a retrospective series of $100 \mathrm{pa}$ tients with soft cervical disc herniations. All were surgically treated and those with radiculopathy only as presenting symptoms had better outcomes than those with combined radicular and spinal cord involvement. Other than presenting symptoms the hernias were not further characterized. Until the work of Yamazaki et al (29), no study had characterized the courses of herniated masses in cervical disc herniations. He found using CT discography that most herniated masses causing myelopathy have median penetration in the deep layer of the longitudinal ligament and oblique courses of herniation are common.

He also noted that among herniated masses causing radiculopathy, most masses took an oblique course from the median penetration to the paramedian or lateral section.

Lateral disc herniation was found to be uncommon where the bony barrier of the uncovertebral junction exists on both 
sides of the disc. If the cervical disc herniates obliquely, it can impinge on the spinal cord, producing myelopathy that may cause upper and lower extremity neurologic signs.

\section{Pathophysiologic Considerations}

Innervation of the cervical intervertebral discs has been shown to be similar to that found in lumbar discs. Cervical sinuvertebral nerves have an upward course in the vertebral canal and supply the disc at their level of entry as well as the more cranial disc (30-32). Both nerve fibers and proprioceptive receptors are found in the outer third of the annulus fibrosus and these have been postulated by Bogduk to be the substrate for primary disc pain in disease and for the pain response of provocative cervical discography (30).

Additionally, there have been advances in the past decade in understanding the biologic aspects of intervertebral disc cell function (33). Disc cellular function produces the extracellular matrix components of the disc, which in turn shape the discs physiologic and biomechanical function. Ongoing research points to the cellular basis of disc degeneration and the very complex intradiscal metabolism involved in the interrelated phenomena of end-plate nutrient diffusion, the role of cytokines in modulating the inflammatory and pain responses of the disc, and how mechanical stimuli modify disc cell activity.

Injuries to the disc may evoke pain by the activation of sensory nociceptors. Injury of the annulus can lead to release of significant amounts of inflammatory chemicals that may in turn irritate or sensitize the annulus and adjacent structures in the spinal canal and intervertebral foramina. Inflammatory and immunological reaction to herniated disc material is well recognized as a pain generating mechanism (34). Determination of a particular disc as the pain-producing site is the goal of cervical discography.

An atypical case presentation of cervical disc herniation causing localized ipsilateral popliteal pain was described by Neo et al (35) in 2002, using MRI as a diagnostic modality. An adult woman gave a four-month history of increasing pain, eventually being unable to stand or walk. Physical examination and conventional radiography could not explain the pain. An MRI examination showed a large disc herniation on the right at $\mathrm{C} 3 / 4$ and narrowing of the spinal canal at $\mathrm{C} 4 / 5$. Following anterior decompression and fusion to prevent impending myelopathy, the popliteal pain resolved immediately and completely. The pain has not recurred in almost three years after surgery. This case exemplifies the infrequent but significant findings that cervical herniations can cause. The utility of discography in solving puzzling presentations of atypical pain resulting from cervical lesions was shown most recently in a patient with atypical cervicogenic headache, reported by Singh (36) in 2004, in which MRI did not disclose the pain-producing lesion. This particular patient had given a six-year history of intractable pain and until the pain-producing lesion was identified by discography, no diagnostic modality or treatment had given any benefit.

Cervical discography has been utilized to establish a diagnosis of cervical angina or pseudoangina which Wells (37) in 1997 reported as chest pain resembling true cardiac pain coming from C7 nerve root compression. Guler et al (38) in 2000 defined cervical angina as chest pain that resembles true cardiac angina but originates from cervical discopathy with nerve root compression. Cervical discography can establish the diagnosis after coexisting coronary artery disease as been ruled out. Guler reported in his paper the first cases of cervical angina associated with acute ECG changes brought on by neck motion. In a more extensive survey Jacobs (39) in 1990 reported his series of 164 patients with cervical angina giving similar presentations.

\section{Rationale ANd Indications}

Discography is not a screening or initial examination in the investigation cervical pain. That role is met by patient history and physical examination, MRI examinations, CT scans, and myelography. Radiographic anatomy disclosed by these techniques is often precise and descriptive but it may not identify the origin of pain and there can be discrepancies between the degree of pain and the apparent severity of changes observed in radiographic images (40). Parfenchuck et al (41) in a 1994 study suggested that while several patterns seen with MRI correlate well with discography findings, others are equivocal. His opinion was that discography was required to diagnose the discogenic pain syndrome. Another study by
Schellhas et al (42), in a 1996 study compared chronic head and neck pain sufferers undergoing MRI or cervical discography. He concluded that discographically normal discs were never painful whereas painful discs exhibited annular tears that often escaped MRI detection and that MRI could not reliably discern the source of discogenic pain. In 1975, Collins (43) noted the useful adjunct role to be played by cervical discography, it being particularly helpful in determining the level of fusion and the selection of patients with cervical discs that needed to be fused.

Cervical discography is indicated for the following situations:

1. Presence of persistent neck pain that usual diagnostic modalities have failed to identify a cause

2. Findings using traditional modalities are equivocal for the cause of pain

3. Planning for surgical fusion requires precise identification of painful levels

4. Persistent pain following fusion requires levels above and below fusion to be examined as pain generators

5. Differentiation cannot be made of scar tissue from recurrent herniation by usual modalities.

Guyer et al (44) delineated indications for lumbar discography in the position statement of the North American Spine Society (NASS) in 1995. Points stressed in the NASS statement define the appropriate use of discography, with attention given that patients may recognize pain provoked in the procedure as similar to or identical with their presenting complaint.

Disc injection has been used for well over two decades to select levels for surgical discectomy and fusion. Riley et al (45) in 1969 used cervical disc injection at the time of surgery, with discometry and epidural leakage being primary diagnostic factors. Simmons and Segil (46) in 1975 used pain responses from saline injection distention of the disc to select disc levels for surgery. Both groups found high percentage rates of success determining the level for surgery. Different groups like Whitecloud and Seago (47), Siebenrock and Aebi (48) and Hubach (49) report similarly high percentage success rates for discectomy and fusion of painful discs at levels diagnosed by discography. When discography was not employed preoperatively, success rates were reported 
only half as high.

Contraindications to cervical discography include: known allergies to contrast dye, suspected or confirmed patient sepsis, infection at the site of injection, known coagulopathy or patient refusal. Symptoms of cord compression or myelopathy are absolute contraindications.

\section{TeChnical Considerations}

Cervical discography is a technique in which proficiency and expertise are essential. The precise detailed knowledge of the anatomy of the cervical spine and the vital structures in the anterior cervical region is of utmost importance. The discographer must be skilled in airway management and cardiovascular resuscitation.

Pre-procedural preparations include the usual pre-operative considerations. However, the most crucial aspect of cervical discography is the review of prior imaging studies of the cervical spine. This procedure should not be performed at any level where spinal cord compression exists, with or without myelopathy. Any cervical disc level revealing spinal cord deformity should be avoided or studied under extreme care, depending upon the individual circumstances.

Prophylactic antibiotics are given within an hour before the procedure begins, usually Cefazolin or a similar antibiotic with known intradiscal diffusion characteristics and activity against Staphylococcal and Streptococcal skin inhabitants.

The procedure is performed with the patient in supine position and with support under the shoulders, the head and neck slightly hyperextended. The disc cannot be entered posteriorly due to the spinal cord or anteriorly because of the trachea. Therefore, entry into the cervical disc is usually done from the right anterolateral approach. Complete aseptic technique is used throughout the procedure. The skin is prepped with iodophon or chlorhexidine solution and the solutions should remain on the skin for at least two minutes to kill any Staphylococcus aureus or Streptococcus epidermidis spp., which are the most common skin bacteria usually implicated in risk of deep tissue infections following skin puncture. An alcohol rinse of the site is done for maximal antibacterial effect.

A right paratracheal approach is used and the C-arm is placed in oblique position and the uncovertebral junction is identified. Unlike lumbar discography, where the disc is punctured on the side opposite the patient's symptoms, a right-sided approach is used by most discographers because of concern of accidental puncture of the esophagus with the left side approach. The skin is anesthetized with $1 \%$ buffered, preservativefree lidocaine. Light IV sedation, usually with midazolam, may be used; however, the patient must always remain alert enough to respond to pain sensations and communicate them. The patient is monitored closely for vasovagal signs, which may be caused by compression of the carotid artery during manual displacement with needle entry. The C-arm is placed in oblique position with a slight cranial angulation to best visualize the disc space.

Skin puncture is made with an 18gauge needle, medial to the anterior border of the sternocleidomastoid muscle, between the carotid sheath and trachea. A 22 gauge 3.5" styleted spinal needle is inserted through the puncture hole and slowly advanced to the target point just medial to the uncovertebral junction of the lower vertebral body. The carotid pulse is palpated and carotid sheath structures are displaced laterally by digital pressure. Additional local anesthetic is given along the needle tract. Slow, deliberate needle advancement is key to the successful procedure. The needle is advanced either into the disc or against the vertebra

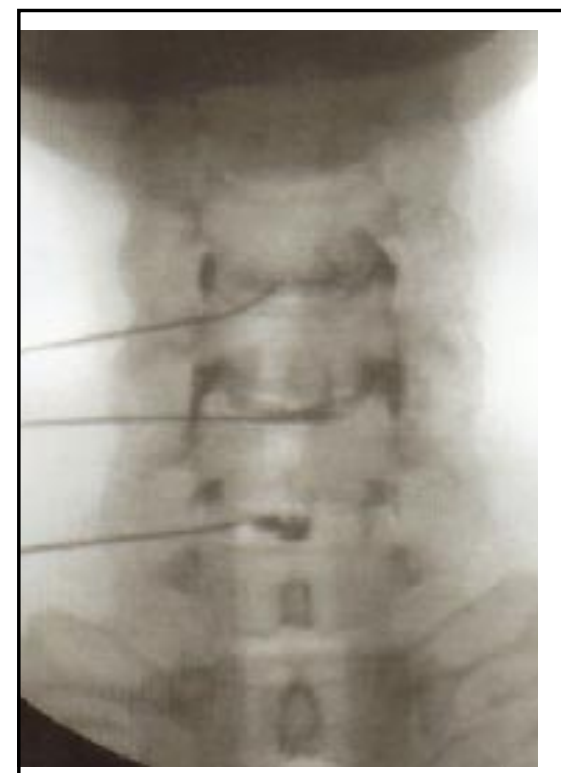

A. AP view adjacent to the disc. The position is confirmed in the AP and lateral projections with the fluoroscope. Careful adjustment and redirection of the needle as necessary is made into the annulus of the disc.

$0.25 \mathrm{~mL}$ to $0.5 \mathrm{~mL}$ contrast solution is injected into the nucleus at each level and the pain response is noted. The discogram is positive when the patient reports concordant pain, pain that closely resembles symptomatic pain in intensity and location. Injection of local anesthetic into a painful disc is used to further evaluate symptomatic relief and confirm a disc as a pain generator. Leakage of contrast out of the disc space is noted, as well as the overall disc appearance. Figure 1 illustrates cervical discography.

Intradiscal antibiotics may be injected at the discretion of the discographer, but with careful attention to leakage of antibiotic solution into the epidural space. Some discographers use antibiotic solution in combination with contrast. It is preferable and safe not to mix antibiotic with contrast and use antibiotic only when the pattern of dye has been fully visualized and subarachnoid spread has been completely ruled out.

\section{INTERPRETATION}

Interpretation of the pain response is the sine quo non of the effective use of cervical discography. Pain is a subjective response that individuals report differently. Pain reporting cannot be objec-

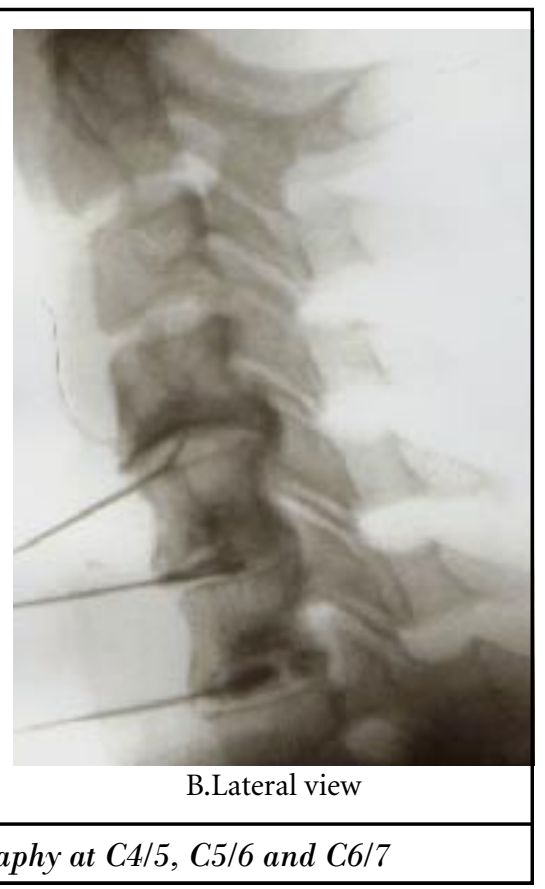


tively treated for bias-free analysis. Various methods have been used to rate the patient pain response; most incorporate self-reporting using a visual analog scale (VAS), an independent observer rating pain appearance and behavior and patient reporting the similarity of injection pain to chronic pain. The alleviation of pain following injection of local anesthetics is recorded to note the analgesic effect in an abnormal disc.

Cervical discography and the pain response was discussed by Klafta and Collis (50). In their work a very low percentage of discs was judged to be normal, as pain occurred in the majority of injections and this was taken as an indicator of disc abnormality but not diagnostic of disc protrusion. A subsequent paper addressed this finding; the authors did not consider pain from injection to be of significance and of concern only if a mass lesion in the disc itself was demonstrable (51). This contrasts with current discographic practice, as exemplified by the report of Ohnmeiss et al (40). Pain response and radiographic appearance of discs showed good agreement, with clinical pain being provoked in $78 \%$ of discs appearing abnormal and in only $14 \%$ of those being normal.

Beginning with the report of Roth (40) in 1976, with discogenic pain being accurately diagnosed prior to surgery by analgesic disc injection, many authors report that the most effective test for the identification and localization of a painful disc is cervical discography. Patients with cervicogenic pain are accurately and consistently diagnosed by cervical discography reproducing their characteristic pain. Other modalities can identify pathology but only discography can correlate abnormalities with pain.

The purpose of the procedure is to identify a source of pain. The information to be recorded for every procedure includes, but not limited to: injection volumes, characteristics of all endpoints of injections reached; pain responses at each level examined on a $0-10$ scale with 0 being no pain and 10 the worst pain possible, and whether the pain felt is identical, similar or not at all the same as the pain which led to the examination; location of pain from the examination; the morphology of the disc revealed by the examination - annular tears, endplate defects, anatomical abnormalities, fissures or leakage of contrast media; correlation of these findings with MRI or CT imaging studies; and an opinion from the discographer concerning the apparent validity of the examination - patient pain response and cooperation in the examination.

Even though the pattern of contrast dispersal is the least important finding in cervical discography, some characteristic patterns of abnormal discs have been described. These include: escape of contrast beneath the longitudinal ligament or into the epidural space reveals rupture of the annulus; a deflated balloon appearance filling the disc space indicates degeneration of the nucleus; escape of contrast through the vertebral end plates shows interosseous herniation; leakage of contrast beneath an unfused ring epiphysis shows vertebral edge separation; escape of contrast into a communicating haemangioma related to end plate fracture.

\section{Complications}

Although very beneficial as a diagnostic tool, the procedure is not without risks (52-60). Complications can occur due to incorrect needle placement in which the hypopharynx, esophagus or even spinal cord could be punctured, with the attendant risks of infection or neurologic damage. Very deliberate and careful needle advancement and good fluoroscopic visualization prevent such occurrences and their sequelae.

Unusual complications are also possible. In one reported case, quadriplegia developed within seconds after injection into the intervertebral space. During the injection the patient reported having severe pain in her arm. Surgical evidence showed sequestered portions of a degenerate disc were pushed into the spinal canal during the examination. Slow recovery of neurologic deficits took place after the operation (58). A recent study of a large group of patients undergoing cervical discography gave a $1.49 \%$ complication rate based on the number of discs injected (54). There were two cases of discitis, one post-injection hematoma and one patient developed headache.

The cord compression syndrome due to soft central disc herniation can be a potential complication with exacerbation of herniation causing myelopathy and even quadriplegia in extreme cases.

Another rare but significant potential complication, that of spinal epidural abscess mimicking disc herniation was reported by Sawada et al (59) in 1996. His patient developed fever, sore throat and nuchalgia with a sudden onset of quadriplegia following partial sigmoidectomy, and MRI showed characteristic findings of a cervical herniation. At discectomy cervical discitis was discovered with an associated spinal epidural abscess. With antibiotic follow up he improved. A high index of suspicion must be accorded any MRI image and associated clinical signs of infection. Discitis, though rare, must remain in the differential diagnosis.

Discitis, one of the most dreaded complications of disc injection is rarely reported and in reviews of the literature, rates of 0.1 to $0.2 \%$ are found. Guyer et al (60) in their series report a rate of infection of 0.1 to $0.5 \%$.

The author typically uses both IV and intradiscal antibiotics for prophylaxis. Although an IV bolus before the procedure can produce antibiotic penetration into the disc, timing of the bolus is critical. Studies have found that the minimum inhibitory concentration (MIC) for the most common agent responsible for discitis, Staphylococcus epidermidis, was not exceeded using cefazolin except in a well-defined time period of 15 to $80 \mathrm{~min}$ utes after an IV bolus (61). Moreover, if the disc has undergone degeneration, it is likely that antibiotic concentrations intradiscally would be further reduced. Thus, intradiscal antibiotics are usually considered (59-67). Studies support the use of appropriate broad-spectrum intradiscal antibiotics to minimize the risk of discitis; typical skin inhabitants Staphylococcus aureus and S. epidermidis are the organisms most likely to be contaminants. Cefazolin has been widely used because of its activity against these organisms and its documented inhibitory levels intradiscally (61).

The argument has been made for the use of intradiscal antibiotics for prophylaxis of disc infection during discography and that with proper timing and choice of antibiotic, intradiscal placement of antibiotic should obviate the need for systemic administration to avoid the risk of generating antibiotic resistance (63-66). Several antibiotics meet the requirement to be above the minimum inhibitory concentration of S. aureus and S. epidermidis, among them cefazolin, gentamycin and clindamycin; ceftriaxone meets this requirement and also has been shown to persist at levels above the MIC for these organisms as long as five hours in the in- 
tervertebral disc space with administration systemically one hour prior to the procedure $(63,67)$.

There are, then, several classes of antibiotics shown to be efficacious. With proper selection and use any allergic or sensitivity reaction should be avoided.

A recent case report by Boswell et al (68) details the first reported post-discography seizures associated with a cephalosporin, cephazolin. Caution would be advised mixing beta-lactam antibiotics or cephalosporins with contrast prior to disc injection. Accidental or inadvertent intrathecal injection with this class of antibiotic may provoke this reaction.

With the exercise of meticulous care at all times, discography can be done with few, if any, complications, when performed under strict aseptic conditions and by physicians well-experienced in the procedure. It is not a procedure to be attempted by the novice, because it is very easy to pass a needle through the disc and into the spinal cord.

\section{CONCLUSION}

Cervical discography is a specialized procedure requiring the skill of a highly trained and competent interventionalist with expertise in the procedure. Diagnostic disc injection may be indicated in the evaluation of patients with symptomatology without a discernible etiology from other imaging studies. Discography is used to determine the presence of pathology and to reproduce pain felt by the patient, so-called concordant pain. It is not a screening procedure but rather a confirmatory one when cervical disc pathology is suspected and is best utilized with MRI and clinical examination.

There is a very low level of reported complications; patient selection, skilled operation and maintenance of sterility are essential. Cervical discography has a unique position in the diagnosis and localization of the painful disc syndrome, correlating MRI findings with symptomatology and in determining the levels for successful surgical fusion of the cervical spine.

\begin{tabular}{|l|} 
Author Affiliation \\
Vijay Singh, MD \\
Medical Director \\
Pain Diagnostics Associates \\
1601 Roosevelt Road \\
Niagara, Wisconsin 54151 \\
E-mail: vsingh@netnet.net \\
\hline
\end{tabular}

\section{REFERENCES}

1. Bogduk N. Neck pain. Aust Fam Physician 1984; 13:26-30.

2. Goodman BW Jr. Neck pain. Prim Care 1988; 15:689-708.

3. Bovim G, Schrader H, Sand T. Neck pain in the general population. Spine 1994; 19: 1307-1309.

4. Radhakrishnan K, Litchy WJ, O'Fallon WM et al. Epidemiology of cervical radiculopathy. A population-based study from Rochester, Minnesota, 1976 through 1990. Brain 1994; 117:325-335. 1990.

5. Motimaya A, Ariei M, George D et al. Diagnostic value of cervical discography in the management of cervical discogenic pain. Conn Med 2000; 64:395-398.

6. Slipman C, Plastaras C, Patel R et al. Provocative cervical discographic symptom mapping. Spine J 2002; 2:112-115.

7. Kaiser JA, Holland BA. Imaging of the cervical spine. Spine 1998; 23:2701-2712.

8. Chevrot A, Drape JL, Godefroy D et al. Imaging the painful cervical spine. J Radiol 2003; 84:181-239.

9. Gelehrter $\mathrm{G}$. The addition of nucleography to discography as an extended method of examination. ROFO Fortschr Geb Roentgenstr Nuklearmed 1975; 122:517-519.

10. Roth DA. Cervical analgesic discography. A new test for the definitive diagnosis of the painful disc syndrome. JAMA 1976; :235: 1713-1715.

11. Lindblom K. Diagnostic puncture of intervertebral discs in sciatica. Acta Orthop Scand 1948; 17:231-239.

12. Schmorl G. Die pathologie der wirbelsaule. Dtsch Orthop Ges 1926; 21:3.

13. Hirsch C. An attempt to diagnose level of disc lesion clinically by disc puncture. Acta Orthop Scand 1948; :18:132-140.

14. Erlacher PR. Nucleopgraphy. J Bone Joint Surg 1952; 34B:204.

15. Smith GW, NicholsP Jr. Technic for cervical discography. Radiology 1957; 68:718720.

16. Cloward RB. Cervical discography. Technique, indications and use in the diagnosis of ruptured cervical discs. AJR 1958;79: 563-574.

17. Holt EP. Fallacy of cervical discography. JAMA 1964;188:799-801.

18. Simmons JW, Aprill CN, Dwyer AP et al. A reassessment of Holt's data. Clin Orthop 1988; 237:120-124.

19. Fortin JD. Precision diagnostic disc injections. Pain Physician 2000; 3:271-288.

20. Bland JH. Basic Anatomy. In Bland JH (ed.) Disorders of the Cervical Spine 2nd ed., Philadelphia, WB Saunders, 1994, pp 41-70.

21. Van Roy P, Barbaix E, Clarijs JP. Functional anatomy of the cervical spine. In Szpalski M, Gunzburg R (ed). The Degenerative Cervical Spine, Philadelphia, Lippincott Williams and Wilkins, 2001, pp 3-27.

22. Saternus KS, Bornscheuer HH. Compara- tive radiologic and pathologic-anatomic studies on the value of discography in the diagnosis of acute intravertebral disc injuries in the cervical spine. ROFO Fortschr Geb Roentgenstr Neuen Bildgeb Verfahr 1983; 139:651-657.

23. Kambin P, Abda S, Kurpicki F. Intradiscal pressure and volume recording: evaluation of normal and abnormal cervical discs. Clin Orthop 1981;146:144-147.

24. Kumaresan S, Yoganandan N, Pintar FA et al. Morphology of young and old cervical spine intervertebral discs tissues. Biomed Sci Instrum 2000; 36:141-146.

25. Mercer S, Bogduk N. The ligaments and annulus fibrosus of human adult cervical intervertebral discs. Spine 1999; 7:619626

26. Pooni JS, Hukins DW, Haris PF et al. Comparison of the structure of human intervertebral discs in the cervical, thoracic and lumbar regions of the spine. Surg Radiol Anat 1986; 8:175-182.

27. Gen H. A clinicopathologic study of cervical intervertebral discs. Part 2: Morphological and roentgenological findings. Nippon Seikeigeka Gakkai Zasshi 1990; 7: 572-582.

28. Dubuisson A, Lenelle J, Stevennaert A. Soft cervical disc herniation: A retrospective study of 100 cases. Acta Neurchir (Wein) 1993; 125:115-119.

29. Yamazaki S, Kokubun S, Ishii $Y$ et al. Courses of cervical disc herniation causing myelopathy or radiculopathy. Spine 2003; 28:1171-1175.

30. Bogduk N, Windsor $M$, Inglis A. The innervation of the cervical intervertebral discs. Spine 1988; 13:2-8.

31. Bogduk N, Tynan W, Wilson AS. The nerve supply to the human lumbar intervertebral disc. J Anat 1981; 132:39-56.

32. Mendel T, Wink CS, Zimny ML. Neural elements in human cervical intervertebral discs. Spine 1992;17:132-135.

33. Gruber HF, Hanley EN Jr. Recent advances in disc cell biology. Spine 2003; 28:186193.

34. Bibby SR, Jones DA, Lee RB et al. The pathophysiology of the intervertebral disc. Joint Bone Spine 2001; 68:537-542.

35. Neo M, Ido, K Sakamoto T et al. Cervical disc herniation causing localized ipsilateral popliteal pain. J Orthop Sci 2002; 7:147150.

36. Singh V. Percutaneous disc decompression for the treatment of chronic atypical cervical discogenic pain. Pain Physician 2004; 7:115-118.

37. Wells P. Cervical angina. Am Fam Physician 1997; 5:2262-2264.

38. Guler N, Bilge M, Eryonucu B et al. Acute ECG changes and chest pain induced by neck motion in patients with cervical hernia - a case report. Angiology 2000; 51: 861-865.

39. Jacobs B. Cervical angina. NY State J Med 1990; 90:8-11. 
40. Ohnmeiss DD, Guyer RD, Maxon SL. The relation between cervical discographic pain responses and radiographic images. Clin J Pain 2000; 16:1-5.

41. Parfenchuck TA, Janssen ME. A correlation of cervical magnetic resonance imaging and discography/computed tomographic discograms. Spine 1994; 18:2819-2825.

42. Schellhas KP, Smith MD, Gundry CR et al. Cervical discogenic pain. Prospective correlation of $\mathrm{MRI}$ and discography in asymptomatic subjects and pain sufferers. Spine 1996; 21:300-311.

43. Collins HR. An evaluation of cervical and lumbar discography. Clin Orthop 1975; 107:133-138.

44. Guyer RD, Ohnmeiss DD. Position statement from North American Spine Society diagnostic and therapeutic committee. Spine 1995; 20:248.

45. Riley LH Jr, Robinson RA, Johnson KA et al. The results of anterior interbody fusion of the cervical spine. Review of 93 consecutive cases. J Neurosurg 1969; 30:127-133.

46. Simmons EH, Segil CM. An evaluation of discography in the localization of symptomatic levels in discogenic disease of the spine. Clin Orthop 1975; 108:57-69.

47. Whitecloud TS, Seago RA. Cervical discogenic syndrome. Results of operative intervention in patients with positive discography. Spine 1987; 2:313-316.

48. Siebenrock KA, Aebi M. Cervical discography in discogenic pain syndrome and its predictive value for cervical fusion. Arch Orthop Trauma Surg 1994; 113:199-203.

49. Hubach P. A prospective study of ante- rior cervical spondylodesis in intervertebral disc disorder. Eur Spine J 1994; 3:209213.

50. Klafta LA Jr., Collis JS Jr. An analysis of cervical discography with surgical verification. J Neurosurg 1969; 30:38-41.

51. Klafta LA, Jr., Collis JS Jr. The diagnostic inaccuracy of the pain response in cervical discography. Cleve Clin Q 1969; 36:35-39.

52. Guyer RD, Ohnmeiss DD, Mason SL et al. Complications of cervical discography: findings in a large series. J Spinal Disord 1997; 10:95-101.

53. Roosen K, Bettag W, Fiebach O. Complications of cervical discography. ROFO Fortschr Geb Roentgenstr Nuklermed 1975; 122:520-527.

54. Grubb SA, Kelly CK. Cervical discography: clinical implications from 12 years experience. Spine 2000; 25:1382-1389.

55. Zeidman SM, Thompson K, Ducker TB. Complications of cervical discography: analysis of 4400 diagnostic disc injections. Neurosurgery 1995; 37:414-417.

56. Fraser RD, Osti OL, Vernon-Roberts B. latrogenic discitis: the role of intravenous antibiotics in prevention and treatment. An experimental study. Spine 1989; 14: 1025-1032.

57. Smith MD, Kim SS. A herniated cervical disc resulting from discography: an unusual complication. I Spinal Disord 1990; 3:392-394.

58. Laun A, Lorenz R, Asgnoli AL. Complications of cervical discography. J Neurosurg Sci 1981; 1:17-20.

59. Sawada M, Iwamura M, Hirata T et al. Cer- vical discitis associated with spinal epidural abscess caused by methicillin-resistant Staphylococcus aureus. Neurol Med Chir (Tokyo) 1996; 36:40-44.

6o. Guyer RD, Collier R, Stith WJ et al. Discitis after discography. Spine 1988; 13:13521354 .

61. Boscardin JB, Ringus JC, Feingold DJ. Human intradiscal levels with cefazolin. Spine 1992; 17:S145-S148.

62. Osti OL, Fraser RD, Vernon-Roberts B. Discitis after discography. The role of prophylactic antibiotics. J Bone Joint Surg $\mathrm{Br}$ 1990; 72:271-274.

63. Lang R, Saba K, Folman Y et al. Penetration of ceftriaxone into the intervertebral disc. J Bone Joint Surg [Am] 1994; 76:689-691.

64. Rhoten RL, Murphy MA, Kalfas IH et al. Antibiotic penetration into cervical discs. Neurosurgery 1995; 37:418-421

65. Riley LH 3rd, Banovac K, Martinez OV et al. Tissue distribution of antibiotics in the intervertebral disc. Spine 1994; 23:2619-2625.

66. Klessig HT, Showsh SA, Sekorski A. The use of intradiscal antibiotics for discography: an in vitro study of gentamycin, cefazolin and clindamycin. Spine 2003; 28: 1735-1738.

67. Lang R, Folman Y, Ravid M et al. Sequential levels of ceftriaxone in intervertebral disc removed as part of scoliosis surgery. Clin Orthop 1995; 315:209-211.

68. Boswell MV, Wolfe JR. Intrathecal cefazolininduced seizures following attempted discography. Pain Physician 2004; 7:103-106. 
